\title{
Clinical and histopathological characteristics of primary and recurrent basal cell carcinoma: a retrospective study of the patients from a tertiary clinical centre in the northern Poland
}

\author{
Anna Płaszczyńska ${ }^{1}$, Robert Skibiński ${ }^{2}$, Martyna Sławińska ${ }^{1}$, Wojciech Biernat ${ }^{3}$, Aleksandra Lesiak ${ }^{4}$, Roman J. Nowicki ${ }^{1}$, \\ Michat Sobjanek $^{1}$
}

\begin{abstract}
${ }^{1}$ Department of Dermatology, Venereology and Allergology, Faculty of Medicine, Medical University of Gdańsk, Gdańsk, Poland ${ }^{2}$ Dermatological Students Scientific Association, Department of Dermatology, Venereology and Allergology, Faculty of Medicine, Medical University of Gdańsk, Gdańsk, Poland

${ }^{3}$ Department of Pathomorphology, Faculty of Medicine, Medical University of Gdańsk, Gdańsk, Poland

${ }^{4}$ Department of Dermatology, Pediatric Dermatology and Oncology Clinic, Faculty of Medicine, Medical University of Lodz, Lodz, Poland Adv Dermatol Allergol 2022; XXXIX (1): 126-131 DOI: https://doi.org/10.5114/ada.2022.113806
\end{abstract}

\begin{abstract}
Introduction: Basal cell carcinoma (BCC) is the most common malignant neoplasm of the skin. Management of patients with recurrent $B C C$ remains a current clinical issue. Data concerning BCC recurrence rates as well as characteristics of this group of patients in the Polish population are scarce.

Aim: Identification and analysis of clinical, epidemiological and histopathological factors influencing BCC recurrence. Material and methods: Histopathological diagnoses of BCC patients treated by surgical methods at the Department of Dermatology, Venereology and Allergology, Medical University of Gdansk, between 2013 and 2018, were retrospectively analysed. The analysis included 1097 tumours diagnosed in 802 patients, of which 1061 were primary BCC (pBCC) and 36 - recurring BCC (rBCC).

Results: In the analysed cohort, rBCCs constituted $3.3 \%$ of cases. $49.8 \%$ of pBCCs occurred in women; while in the rBCC group $-47.2 \%$. The most common histopathological type was infiltrative BCC, however, it was significantly more prevalent in rBCCs (36.9\% and $52.8 \%$, respectively). The average maximum size of pBCC was $12.3 \pm 8.8 \mathrm{~mm}$, while of rBCC $18.4 \pm 15.1 \mathrm{~mm}(p=0.036)$. The most common location of both $\mathrm{pBCC}$ and rBCC was the nose (tumours in this localization constituted $23.2 \%$ and $25.0 \%$, respectively).

Conclusions: In the analysed cohort a relatively low percentage of rBCC was found. Among analysed risk factors, the most important ones were the infiltrative histopathological type of BCC and the non-radical treatment of the primary tumour.
\end{abstract}

Key words: basal cell carcinoma, local recurrence, risk factors.

\section{Introduction}

Basal cell carcinoma (BCC) is the most common malignant neoplasm of the skin. Due to local invasiveness and very rare occurrence of metastases, this cancer is associated with good prognosis. The incidence of BCC is increasing worldwide [1]. In Poland, there are no accurate statistical data regarding its occurrence as it is classified together with other skin cancers. According to the literature, BCC recurrence rates after surgical treatment, depending on the radicality of tumour excision, range from $1.3 \%$ to $46 \%$ [2-14].

The treatment of patients with rBCC remains a current clinical problem. Accurate recognition of recurrence risk factors is important and facilitates the decision concerning primary tumour management and further ob-

Address for correspondence: Martyna Sławińska MD, PhD, Department of Dermatology, Venereology and Allergology, Faculty of Medicine, Medical University of Gdańsk, 17 Smoluchowskiego St, 80-214 Gdańsk, Poland, phone: +48 585844014, e-mail: mslawinska@gumed.edu.pl

Received: 21.10.2020, accepted: 19.11.2020. 
servation of the patient after treatment. To the best of our knowledge, only a few reports concerned rBCC in the Polish population [3-5, 15].

\section{Aim}

The aim of this study was identification and analysis of clinical, epidemiological and histopathological factors influencing BCC recurrence.

\section{Material and methods}

We retrospectively analysed the results of histopathological reports of patients treated by surgical methods due to BCC at the Department of Dermatology, Venereology and Allergology, Medical University of Gdansk (Poland), between 2013 and 2018.

Histopathological diagnoses were rendered based on the assessment of the routinely (haematoxylin and eosin) stained sections, according to the classification system of the World Health Organization (WHO) [16]. In the collected material we identified 1097 tumours among 802 patients, 1061 of which were primary BCC (pBCC) and 36 were recurring BCC (rBCC). All of the analysed BCCs underwent standard surgical excision.

\section{Statistical analysis}

In the second stage of the study we compared selected clinical variables in both samples. The data were obtained retrospectively, based on medical records. Statistical analysis was performed with the Mann-Whitney $U$-test and $\chi^{2}$ test, using the Statistica software package (v10; StatSoft). Significance was set at $p<0.05$.

\section{Results}

In our study the BCC recurrence rate was 3.3\%. The mean age of the patients with $\mathrm{PBCC}$ was $71.1 \pm 12.3$ and for the group with $r B C C-70.7 \pm 12.3$ years. $49.8 \%$ of $p B C C s$ occurred in women; while in $\mathrm{rBCC}$ group $-47.2 \%$. There were no significant differences in sex and age distribution among primary and recurrent BCCs. In both groups the most common anatomical location was the nose, which accounted for $23.2 \%(n=246)$ of pBCC and $25.0 \%(n=9)$ of rBCC. The average maximum size was significantly larger in recurrent lesions $(p=0.036)$ and measured $18.4 \pm 15.1$ $\mathrm{mm}$ (while in the primary tumour $12.3 \pm 8.8 \mathrm{~mm}$ ).

The most common histopathological type in both groups was infiltrative BCC. This variant occurred significantly more often in the rBCC group $(p=0.04)$ and constituted $52.8 \%(n=19)$. In the group of primary lesions the percentage was $36.9 \%(n=392)$. Consecutive

Table 1. Histopathological type of the analysed BCCS

\begin{tabular}{|c|c|c|c|c|c|c|}
\hline \multirow[t]{2}{*}{ Histopathological type } & \multicolumn{2}{|c|}{$\mathrm{pBCC}$} & \multicolumn{2}{|c|}{$\mathrm{rBCC}$} & \multicolumn{2}{|c|}{ All } \\
\hline & $n$ & $\%$ & $n$ & $\%$ & $n$ & $\%$ \\
\hline Infiltrative & 392 & 36.9 & 19 & 52.8 & 411 & 37.5 \\
\hline Mixed & 229 & 21.6 & 6 & 16.7 & 235 & 21.4 \\
\hline Nodular & 198 & 18.7 & - & - & 198 & 18 \\
\hline Superficial & 160 & 15.1 & 8 & 22.2 & 168 & 15.3 \\
\hline Metatypical & 8 & 0.8 & - & - & 8 & 0.7 \\
\hline Cystic & 2 & 0.2 & - & - & 2 & 0.2 \\
\hline Morpheaform & 2 & 0.2 & - & - & 2 & 0.2 \\
\hline Unidentified & 70 & 6.6 & 3 & 8.3 & 73 & 6.7 \\
\hline All & 1061 & 100 & 36 & 100 & 1097 & 100 \\
\hline
\end{tabular}

Table 2. Histopathological components of mixed BCC in primary and recurrent BCC groups

\begin{tabular}{lccc}
\hline Histopathological components & $\begin{array}{l}\mathrm{pBCC} \\
n(\%)\end{array}$ & $\begin{array}{l}\text { rBCC } \\
n(\%)\end{array}$ & $\begin{array}{c}\text { All } \\
n(\%)\end{array}$ \\
\hline Nodular-infiltrative & $156(68.1)$ & $3(50)$ & $159(67.7)$ \\
\hline Superficial-infiltrative & $47(20.5)$ & $1(16.7)$ & $48(20.4)$ \\
\hline Nodular-superficial & $17(7.4)$ & - & $17(7.2)$ \\
\hline Desmoplastic infiltrative & $4(1.7)$ & $1(16.7)$ & $5(2.1)$ \\
\hline Nodular-cystic & $4(1.7)$ & $1(16.7)$ & $5(2.1)$ \\
\hline Superficial- morpheaform & $1(0.4)$ & - & $1(0.4)$ \\
\hline All & $229(100)$ & $6(100)$ & $235(100)$ \\
\hline
\end{tabular}


histopathological variants in the pBCC group were: mixed $(21.6 \% ; n=229)$ and nodular type $(18.7 \% ; n=198)$, while in the rBCC group - superficial $(22.2 \% ; n=8)$ and mixed type $(16.7 \% ; n=6)$ (Table 1$)$. The nodular variant was significantly more prevalent in the $\mathrm{BBCC}$ group $(p=0.004)$ and did not occur in the rBCC group.

Further analysis of BCCS revealing mixed histopathological architecture showed that the most frequent subtype in both $\mathrm{pBCCs}$ and $\mathrm{rBCCs}$ was nodular-infiltrative one (pBCC - 68.1\%, $n=156$; rBCC - 50.0\%, $n=3$ ) (Table 2).

Mixed-architecture tumours composed of at least one high risk component (infiltrative, metatypical or morpheaform) constituted $57.5 \%(n=610)$ of pBCC and $66.7 \%(n=24)$ of rBCC.

We also considered anatomical distribution of tumours depending on the location within the high-risk area (nose, preauricular and postauricular skin, ears, temple, lips, eyes, chin, mandible, labionasal fold, feet, palms and genitalia), medium-risk area (forehead, scalp, cheeks, neck, pretibial) and low-risk area (trunk and extremities) $[17,18]$. We did not find significant differences between $\mathrm{pBCC}$ and $\mathrm{rBCC}$ groups (Table 3 ).

In the group of patients with recurrent tumours we analysed the previous treatment of corresponding pBCC (Table 4). Most lesions had been initially surgically excised, in most cases the previous excision was incomplete $(n=11)$. Two patients had histopathological results of complete initial excision and 8 were treated with cryodestruction. There were insufficient data on 11 patients who moved to another care centre. We have also analysed the number of recurrences and the most frequent was one relapse $(77.8 \%, n=28) ; 2$ recurrences were found in 4 (11.1\%) patients, 3 recurrences in 2 (5.6\%) patients and 5 relapses in 1 (2.8\%) patient.

When analysing the completeness of excision in the study group, in 68 (6.2\%) procedures the tumour was excised incompletely, which concerned 60 (5.7\%) primary tumours and 8 (22.2\%) recurrent BCCs. We gathered in-

Table 3. Anatomical distribution of $\mathrm{pBCC}$ and $\mathrm{rBCC}$ depending on the risk area

\begin{tabular}{llll}
\hline Area & pBCC & rBCC & $P$-value \\
\hline $\mathrm{H}$ area & $57.7 \%$ & $47.2 \%$ & $\mathrm{~ns}$ \\
\hline $\mathrm{M}$ area & $27.0 \%$ & $41.7 \%$ & $\mathrm{~ns}$ \\
\hline $\mathrm{L}$ area & $15.3 \%$ & $11.1 \%$ & $\mathrm{~ns}$ \\
\hline
\end{tabular}

formation of these patients and their further treatment process. In 10 cases ( 6 pBCC and 4 rBCC) the tumour relapsed, what constituted $14.7 \%$ of incomplete excisions ( $8.8 \%$ of pBCC and $5.9 \%$ of $r B C C)$. The relapse onset ranged from 1 month to 4 years.

\section{Discussion}

In the present study we have found a relatively low percentage of recurrent BCCs (3.3\%). In the literature the tumour recurrence rate reported ranged from $1.3 \%$ to $46 \%$ [2-14]. The most important factor affecting the risk of recurrence seems to be completeness of the primary resection.

In case of high-risk tumours or in difficult anatomical location, Mohs micrographic surgery (MMS) is the treatment of choice [19]. Unfortunately, it is still not available in many centres. Similarly, our analysis included only patients treated with standard surgical excision. Mosterd et al. [6] in their paper compared MMS and standard surgical excision. A 5-year recurrence rate for pBCC after MMS was $2.5 \%$ and after standard surgical excision $4.1 \%$, while for rBCC $-2.4 \%$ and $12.1 \%$, respectively. Van Loo et al. [7] who continued the study for the next 10 years found out that the recurrence rate for $\mathrm{pBCC}$ after MMS was $4.4 \%$ and after standard surgical excision $12.2 \%$, while for rBCC, $3.9 \%$ and $13.5 \%$, respectively. In the study of Tourli et al. [8] which included 1750 tumours, $77 \%$ were treated with MMS and in $22.8 \%$ wide excision was performed. The percentage of recurrence in the pBCC group after MMS was $0.23 \%$ and after wide excision was $1.4 \%$. In case of secondary BCC, it was $4.7 \%$ and $28.2 \%$, respectively. In previous two epidemiological studies concerning NMSC (BCC and squamous cell carcinoma) conducted in the Medical University of Gdansk the recurrence rates were 3.7\% for low-risk tumours, 5.2\% for high-risk tumours, and $5.5 \%$ for patients over 75 years old [20, 21]. In other Polish studies, BCC recurrence rate after standard surgical excision ranged between $9 \%$ and 19\% [4, 5]. We have not found any Polish studies concerning BCC recurrence rate after MMS.

A relatively low recurrence rate in our study, despite the lack of MMS, could be explained by detailed clinical and videodermoscopic assessment of the patient prior to the surgical procedure (Figure 1), despite the fact that some patients were lost from the follow-up, which could have also affected the percentage of recurrent tumours

Table 4. Method of primary BCC treatment in the group of recurrent tumours

\begin{tabular}{|c|c|c|c|c|c|c|c|c|}
\hline \multirow{2}{*}{ 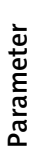 } & \multicolumn{3}{|c|}{ Surgical excision } & \multirow[t]{2}{*}{ Cryodestruction } & \multirow[t]{2}{*}{$\mathrm{CO}_{2}$ laser } & \multirow{2}{*}{$\begin{array}{l}\text { Cryodestruction+ } \\
\mathrm{CO}_{2} \text { laser }\end{array}$} & \multirow[t]{2}{*}{ No data } & \multirow[t]{2}{*}{ All } \\
\hline & Incomplete & Complete & $\begin{array}{l}\text { No } \\
\text { data }\end{array}$ & & & & & \\
\hline$n$ & 11 & 2 & 11 & 8 & 1 & 1 & 2 & 36 \\
\hline$\%$ & 30.6 & 5.6 & 30.6 & 22.2 & 2.8 & 2.8 & 5.6 & 100 \\
\hline
\end{tabular}



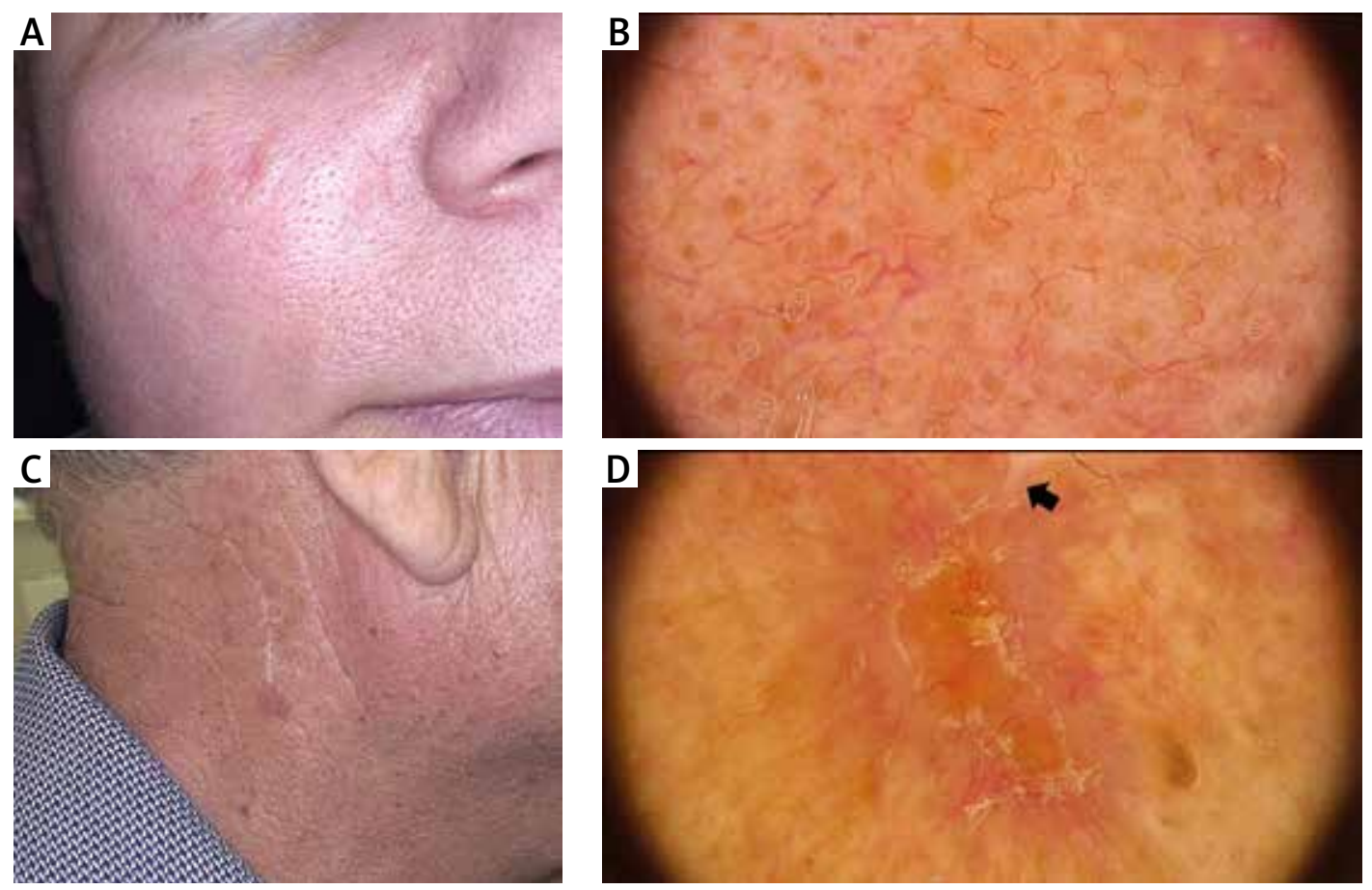

Figure 1. Dermoscopy/videodermoscopy improves preoperative assessment of a patient with basal cell carcinoma (BCC). A - Poorly circumscribed infiltrative BCC on the cheek. B - A typical dermoscopic pattern of arborizing vessels and interruption of the normal skin texture helped to determine the tumour border which differed grossly from the visible border of the lesion (Fotofinder, 20x magnification, non-polarized dermoscopy); C - A reddish tumour arising in line with the scar after previous BCC excision; D - Videodermoscopy shows a yellow, structureless area corresponding with the presence of ulceration and typical arborizing vessels in continuity with the surgical scar (arrow), what confirms the diagnosis of BCC recurrence (Fotofinder, 20x magnification, non-polarized dermoscopy)

in the studied group. According to the study by Caresana and Giardini [22], preoperative dermoscopic assessment of BCC improves the determination of tumour border. In the mentioned study, clinical and dermoscopic assessment was compatible in $65.5 \%$ of cases, in the remaining tumours dermoscopic assessment revealed that clinically determined margins were inadequate. According to the authors, the identification of the peripheral BCC borders is characterized by the interruption of the normal skin texture by tumour proliferation and any BCC dermoscopic pattern. However, the usefulness of this method is limited in case of persistent or recurrent BCC, due to the scarring altering the normal skin texture. Beyond dermoscopy, reflectance confocal microscopy (RCM) could also be useful in determination of BCC margin. In a study by Pan et al. [23], RCM used in the assessment of tumour borders in 13 cases was compatible with frozen biopsy in $92.3 \%$. The key feature of the tumour margin in RCM is the presence of tumour islands. The limitation of the method is the depth of penetration limited to the superficial dermis, and thus it can be insufficient in determining the basal margin of the tumour. RCM is also more sensitive than dermoscopy in the assessment of subclinical BCC recurrences [24].
In the present study the size of $\mathrm{rBCC}$ was significantly larger than the primary lesion. This is in line with the previous studies, which showed that recurrences may be associated with a greater proliferation index compared to primary tumours $[15,25]$. In a study conducted by IIjin et al. [15] concerning recurrent BCC of the eyelid, the authors reported higher values of Ki-67 index in rBCC (11-48\%) compared to pBCC (1-20\%).

Apart from revealing a higher proliferation rate, rBCCs often represent more aggressive histopathological architecture than primary tumours. Boulinguez et al. [26] reported that $20 \%$ of initially non-aggressive BCCs became aggressive during recurrence. Bartoš et al. [9] found more aggressive histopathological features in $16.7 \%$ of recurrences compared to corresponding PBCC. Surprisingly, $20.8 \%$ of rBCC represented more benign histopathological architecture than primary tumours.

The vast majority of studies showed that the most common histopathological variant is nodular BCC $[4,10$, 11]. In a study by Troeltzsch et al. [12], among all BCCs the most common variant was also nodular one, while in the group of recurrences - an infiltrative one. In the present study, the most frequent was the infiltrative type in both pBCC and rBCC groups, however, it was significantly more prevalent in rBCCs. Nodular BCCs were third in inci- 
dence in primary tumours and did not occur in the rBCC group. In the group of $\mathrm{pBCC}$ the second most common histopathological type and third in rBCC was the mixed type. The study conducted by Cohen et al. [27] showed that the mixed type of BCC accounted for 43\% (49 tumours of 114 evaluated). In other studies, the frequency of mixed BCC ranged from $15 \%$ to $35.1 \%$ [4, 8, 28-30]. As shown, the mixed type of tumour is relatively common and can cause some management difficulties, thus influencing the recurrence rates.

For example, initial histopathological assessment based on the partial tumour biopsy may not be representative for the whole tumour and application of the treatment method recommended only for non-aggressive BCC (for instance imiquimod or cryodestruction) may lead to higher rates of recurrences [27]. In the study by KamyabHesari et al. [28], the concordance between histopathological results obtained based on trial biopsy and based on the complete excision was $72.3 \%$.

In the present study, the most common anatomical location was the nose for both pBCC and rBCC. Szewczyk et al. [4] reported that the nose and the cheek were the most common location for primary tumours and relapses. According to a study by Mosterd et al. [6], most pBCC occurred in the perinasal region, while $r B C C$ in temporal and frontal areas. In our analysis of BCC distribution, the highest percentage of lesions occurred in the high-risk area, in both $\mathrm{pBCC}$ and $\mathrm{rBCC}$ groups, with no significant differences. In a study by Bartoš et al. [9], rBCC located in high-, intermediate- and low-risk areas comprised respectively $58.1 \%, 35.5 \%$, and $6.4 \%$.

Based on the literature data, the main risk factor for $B C C$ recurrence seems to be non-radical surgical excision. In our study, the incomplete procedures were reported in $11(30.6 \%)$ cases of primary tumours later resulting in recurrence. According to Sartore et al. [11], the risk of recurrence increases approximately 16 -fold with a positive deep and lateral margin and separately 9.5 -fold for the deep margin and 9.0-fold for the lateral margin. Besides that, it was shown that the histopathological result indicating completeness of excision does not exclude the possibility of recurrence. In our study, there were 2 patients with initial complete excision, later diagnosed with recurrence. The samples of tissues of margins after surgical excision are verified in the random vertical section, while after MMS in horizontal slides, which enables the assessment of the entire margin [6, 29-31]. This explains lower BCC recurrence rates in centres using MMS. Moreover, the surgical treatment is more difficult in $\mathrm{rBCC}$, due to the alternations in tissue architecture and scar affecting the clinical margin assessment.

The rate of reported incomplete excisions varies between $4.5 \%$ and $12.2 \%$ and correlates with a high risk of recurrence [13, 32]. Nagore et al. [14] reported relapse after standard surgical excision in $26 \%$ of incompletely excised BCC and in 14\% of completely resected tumours in 5-year follow-up. After a non-radical procedure, the residues of $B C C$ do not always result in tumour recurrence [33-36]. It is probably connected with the immunogenic character of the tumour. Previous studies have shown that spontaneous $B C C$ regression is mediated mainly by CD4+ lymphocytes [34-36]. According to the European guidelines [37], a patient after non-radical excision of an aggressive histopathological variant of BCC or another high-risk factor of recurrence (e.g. mid-face location or positive deep surgical margin) should undergo the second surgery to extend the margin. In the case of non-aggressive, small lesion localized on the trunk, further proceeding could be observation on follow-up visits. American (National Comprehensive Cancer Network, NCCN) guidelines in case of non-radical excision of high-risk BCC recommend either MMS/resection with complete circumferential margin assessment or radiotherapy. Low-risk BCC with a positive margin should be treated in a similar way but radiotherapy should be reserved for non-surgical patients; additionally, secondary standard surgical excision for the lesion in the low-risk area is acceptable [18].

Most recurrences (70.8-77.1\%) occur within the 3 years after treatment, mainly in the first year [9, 11]. Miszczyk et al. [3] showed the rate of recurrence of $42 \%$ within the first year, 26\% within the second year, 17\% within the third year, $7 \%$ during the fourth and $5 \%$ in the fifth year. It is reflected in the current guidelines concerning management of BCC patients. According to the Polish recommendations, follow-up visits should be performed every 3-6 months during the first 3 years and then every 6-12 months [17]. European guidelines recommend follow-up visits every 6-12 months during 3-5 years [37]. According to American (NCCN) guidelines, assessment every 6-12 months during 5 years after treatment is recommended [18].

\section{Conclusions}

In the analysed cohort a relatively low percentage of rBCC was found. Among analysed risk factors, the most important ones were the infiltrative histopathological type of BCC and the non-radical treatment of the primary tumour.

\section{Acknowledgments}

Funding sources that supported the work: Publication cost supported in part from Santander Universidades Scholarship (2020) awarded to Anna Płaszczyńska and Robert Skibiński and in part funded by the Medical University of Gdansk, Project No. 02-0066/07/253.

\section{Conflict of interest}

The authors declare no conflict of interest. 


\section{References}

1. Lomas A, Leonardi-Bee J, Bath-Hextall F. A systematic review of worldwide incidence of nonmelanoma skin cancer. Br J Dermatol 2012; 166: 1069-80.

2. Griffiths RW, Suvarna SK, Stone J. Do basal cell carcinomas recur after complete conventional surgical excision? Br J Plast Surg 2005; 58: 795-805.

3. Miszczyk J, Charytonowicz M, Dębski T, Noszczyk B. Incomplete excision of basal cell carcinoma (BCC) in the head and neck region: to wait, or not to wait? Adv Dermatol Allergol 2017; 34: 607-11.

4. Szewczyk MP, Pazdrowski J, Dańczak-Pazdrowska A, et al. Analysis of selected recurrence risk factors after treatment of head and neck basal cell carcinoma. Adv Dermatol Allergol 2014; 31: 146-51.

5. Pazdrowski J, Dańczak-Pazdrowska A, Golusiński P, et al. The recurrence of facial basal cell carcinoma in patients treated at the Head and Neck Surgery Ward and Laryngological Oncology Clinic of the Greater Poland Cancer Centre in the years 2007-2010. Otolaryngol Pol 2012; 66: 185-90.

6. Mosterd K, Krekels GA, Nieman FH, et al. Surgical excision versus Mohs' micrographic surgery for primary and recurrent basal-cell carcinoma of the face: a prospective randomised controlled trial with 5-years' follow-up. Lancet Oncol 2008; 9: 1149-56.

7. van Loo E, Mosterd K, Krekels GA, et al. Surgical excision versus Mohs' micrographic surgery for basal cell carcinoma of the face: a randomised clinical trial with 10 year follow-up. Eur J Cancer 2014; 50: 3011-20.

8. Tourli IA, Langner D, Haroske G, et al. Basal cell carcinoma of the head-and-neck region. A single center analysis of 1,750 tumors. Georgian Med News 2016; 250: 38-44.

9. Bartoš V, Pokorný D, Zacharová O, et al. Recurrent basal cell carcinoma: a clinicopathological study and evaluation of histomorphological findings in primary and recurrent lesions. Acta Dermatovenerol Alp Pannonica Adriat 2011; 20: 67-75.

10. Rieger KE, Linos E, Egbert BM, Swetter SM. Recurrence rates associated with incompletely excised low-risk nonmelanoma skin cancer. J Cutan Pathol 2010; 37: 59-67.

11. Sartore L, Lancerotto L, Salmaso M, et al. Facial basal cell carcinoma: analysis of recurrence and follow-up strategies. Oncol Rep 2011; 26: 1423-9.

12. Troeltzsch M, Probst FA, Knösel T, et al. Clinical and pathologic parameters predicting recurrence of facial basal cell carcinoma: a retrospective audit in an advanced care center. Int J Dermatol 2016; 55: 1281-8.

13. Lara F, Santamaría JR, Garbers LE. Recurrence rate of basal cell carcinoma with positive histopathological margins and related risk factors. An Bras Dermatol 2017; 92: 58-62.

14. Nagore E, Grau C, Molinero J, Fortea JM. Positive margins in basal cell carcinoma: relationship to clinical features and recurrence risk. A retrospective study of 248 patients. J Eur Acad Dermatol Venereol 2003; 17: 167-70.

15. Iljin A, Zieliński T, Antoszewski B, Sporny S. Clinicopathological analysis of recurrent basal cell carcinoma of the eyelid. Adv Dermatol Allergol 2016; 33: 42-6.

16. LeBoit PE, Burg G, Weedon D, Sarasin A. Skin Tumors: Pathology and Genetics. IARC Press. Lyon, France 2006.

17. Lesiak A, Czuwara J, Kamińska-Winciorek G, et al. Basal cell carcinoma. Diagnostic and therapeutic recommendations of the Polish Dermatological Society. Dermatol Rev 2019; 106: 107-26.

18. National Comprehensive Cancer Network (NCCN). Clinical Practice Guidelines in Oncology: Basal Cell Skin Cancer V.I.2018.
19. Clark CM, Furniss M, Mackay-Wiggan JM. Basal cell carcinoma: an evidence-based treatment update. Am J Clin Dermatol 2014; 15: 197-216

20. Włodarkiewicz A, Kozicka D, Michajłowski I, et al. Skin cancer - epidemiological, clinical and surgical treatment analysis of 1406 patients. Dermatol Rev 2011; 98: 104-11.

21. Sobjanek M, Michajłowski I, Malek M, et al. Skin cancer in the elderly - epidemiological, clinical and surgical treatment analysis of 254 patients. Adv Dermatol Allergol 2012; 29: 407-10.

22. Caresana G, Giardini R. Dermoscopy-guided surgery in basal cell carcinoma. J Eur Acad Dermatol Venereol 2010; 24: 1395-9.

23. Pan ZY, Lin JR, Cheng TT, et al. In vivo reflectance confocal microscopy of basal cell carcinoma: feasibility of preoperative mapping of cancer margins. Dermatol Surg 2012; 38: 1945-50.

24. Yuksel El, Gurel MS, Erdemir AT, et al. The reflectance confocal microscopy in diagnosis of recurrent basal cell carcinoma. J Dermatolog Treat 2016; 27: 182-90.

25. Kazantseva IA, Khlebnikova AN, Babaev VR. Immunohistochemical study of primary and recurrent basal cell and metatypical carcinoma of the skin. Am J Dermatopathol 1996; 18: 35-42.

26. Boulinguez S, Grison-Tabone C, Lamant L, et al. Histological evolution of recurrent basal cell carcinoma and therapeutic implications for incompletely excised lesions. Br J Dermatol 2004; 151: 623-6.

27. Cohen PR, Schulze KE, Nelson BR. Basal cell carcinoma with mixed histology: a possible pathogenesis for recurrent skin cancer. Dermatol Surg 2006; 32: 542-51.

28. Kamyab-Hesari K, Seirafi H, Naraghi ZS, et al. Diagnostic accuracy of punch biopsy in subtyping basal cell carcinoma. J Eur Acad Dermatol Venereol 2014; 28: 250-3.

29. Bartoš V, Kullová M. Basal cell carcinoma of the skin with mixed histomorphology: a comparative study. Cesk Patol 2016; 52: 222-6.

30. Ghanadan A, Abbasi A, Rabet M, et al. Characteristics of mixed type basal cell carcinoma in comparison to other BCC subtypes. Indian J Dermatol 2014; 59: 56-9.

31. Portela PS, Teixeira DA, Machado CDAS, et al. Horizontal histological sections in the preliminary evaluation of basal cell carcinoma submitted to Mohs micrographic surgery. An Bras Dermatol 2019; 94: 671-6.

32. Kumar P, Watson S, Brain AN, et al. Incomplete excision of basal cell carcinoma: a prospective multicentre audit. Br J Plast Surg 2002; 55: 616-22.

33. Swetter SM, Boldrick JC, Pierre P, et al. Effects of biopsy-induced wound healing on residual basal cell and squamous cell carcinomas: rate of tumor regression in excisional specimens. J Cutan Pathol 2003; 30: 139-46.

34. Wong DA, Bishop GA, Lowes MA, et al. Cytokine profiles in spontaneously regressing basal cell carcinomas. Br J Dermatol 2000; 143: 91-8.

35. Hunt MJ, Halliday GM, Weedon D, et al. Regression in basal cell carcinoma: an immunohistochemical analysis. Br J Dermatol 1994; 130: 1-8.

36. Halliday GM, Patel A, Hunt MJ, et al. Spontaneous regression of human melanoma/nonmelanoma skin cancer: association with infiltrating CD4+ T cells. World J Surg 1995; 19: 352-8.

37. Peris K, Fargnoli MC, Garbe C, et al. Diagnosis and treatment of basal cell carcinoma: European consensus-based interdisciplinary guidelines. Eur J Cancer 2019; 118: 10-34. 